\title{
Unilateral Adrenal Hemorrhage and the Challenge Of Early Recognition
}

Resheed Alkhiari MBBS, Dana Attar MBBS, Christian Kraeker, MD

\section{About the Author}

Resheed Alkhiari is a PGY4 in Gastroenterology at McMaster University and Teaching Assistant at Qassim University, Saudi Arabia. Dana Attar is a PGY4 Endocrinology at McGill University, Montreal, Québec, Canada and Christian Kraeker is an Assistant professor in General Internal Medicine at McMaster University, in Hamilton, Ontario, Canada. Correspondence may be directed to Resheed.Alkhiari@medportal.ca.

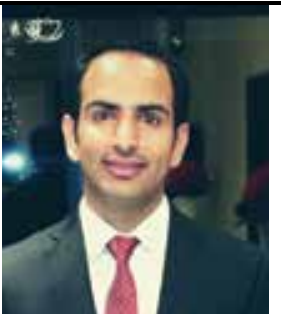

Alkhiari

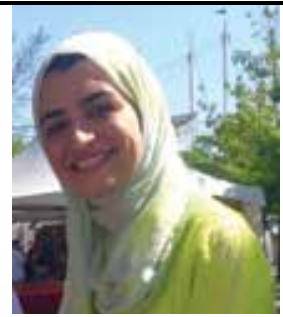

Attar

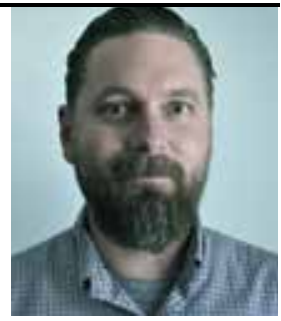

Kraeker

\section{Summary}

Adrenal hemorrhage $(\mathrm{AH})$ is a rare condition with an estimated prevalence of $1 \%$ among hospital-based autopsies. It is usually discovered incidentally on computed tomography. ${ }^{1}$ Most cases are associated with the use of anticoagulation, especially in the setting of heparin-induced thrombocytopenia, anti-phospholipid antibody syndrome, trauma, metastatic disease, sepsis, and critical illness. ${ }^{5-7}$ We report a case of acute unilateral adrenal hemorrhage associated with Escherichia coli pyelonephritis in the context of recent prolonged steroid use.

\section{Résumé}

L'hémorragie surrénalienne (adrenal hemorrhage ou $\mathrm{AH}$ ) est une pathologie rare dont la prévalence est estimée à $1 \%$ sur les autopsies réalisées en milieu hospitalier. Elle est habituellement remarquée de manière accidentelle lors d'une tomodensitométrie ${ }^{1}$. La plupart des cas sont associés à l'usage d'anticoagulants, en particulier en situation de thrombocytopénie induite par l'héparine, de syndrome d'anticorps antiphospholipides, de trauma, de maladie métastatique, de septicémie ou de maladie grave $e^{5-7}$. Nous décrivons ici un cas d'hémorragie surrénalienne unilatérale aiguë associée à une pyélonéphrite due à Escherichia coli dans un contexte d'usage prolongé récent de stéroïdes.

\section{Case Report}

An 87-year-old woman presented to the emergency department with a four-day history of generalized weakness, dysuria, and fever. Her past medical history was significant for osteoarthritis, osteoporosis, and polymyalgia rheumatica, for which she was treated with prednisone that had been reduced gradually over two years and completely discontinued four months prior to presentation. Her medications included vitamin $\mathrm{D}$, calcium, and naproxen. On examination, she was alert and oriented. Her body temperature was $37.7 \mathrm{C}$, pulse rate was 107 beats/ min, and blood pressure was $139 / 69 \mathrm{~mm} \mathrm{Hg}$ without any postural change. Her abdomen was soft to palpation with mild tenderness in the right upper quadrant. There was no skin discoloration. Initial workup revealed a hemoglobin of
$125 \mathrm{~g} / \mathrm{L}$, a leukocyte count of $30.2 \times 10^{3} / \mathrm{L}$, and a platelet count of $203 \times 10^{9} / \mathrm{L}$. Serum sodium was $135 \mathrm{mmol} / \mathrm{L}$, potassium 5 $\mathrm{mmol} / \mathrm{L}$, blood urea nitrogen $26 \mathrm{mmol} / \mathrm{L}$, and creatinine 388 $\mu \mathrm{mol} / \mathrm{L}$. Urinalysis was positive for nitrites and showed more than 30 leukocytes per high power field, and urine culture revealed the presence of a pan-sensitive Escherichia coli. Also, two peripheral blood cultures were negative.

The working diagnosis of a complicated urinary tract infection was made and intravenous ceftriaxone and fluids were started immediately, in addition to venous thromboembolism (VTE) prophylaxis with unfractionated heparin 5000 IU BID subcutaneously. Unfortunately there was no significant improvement in her condition over the first three days despite appropriate antibiotic therapy. 


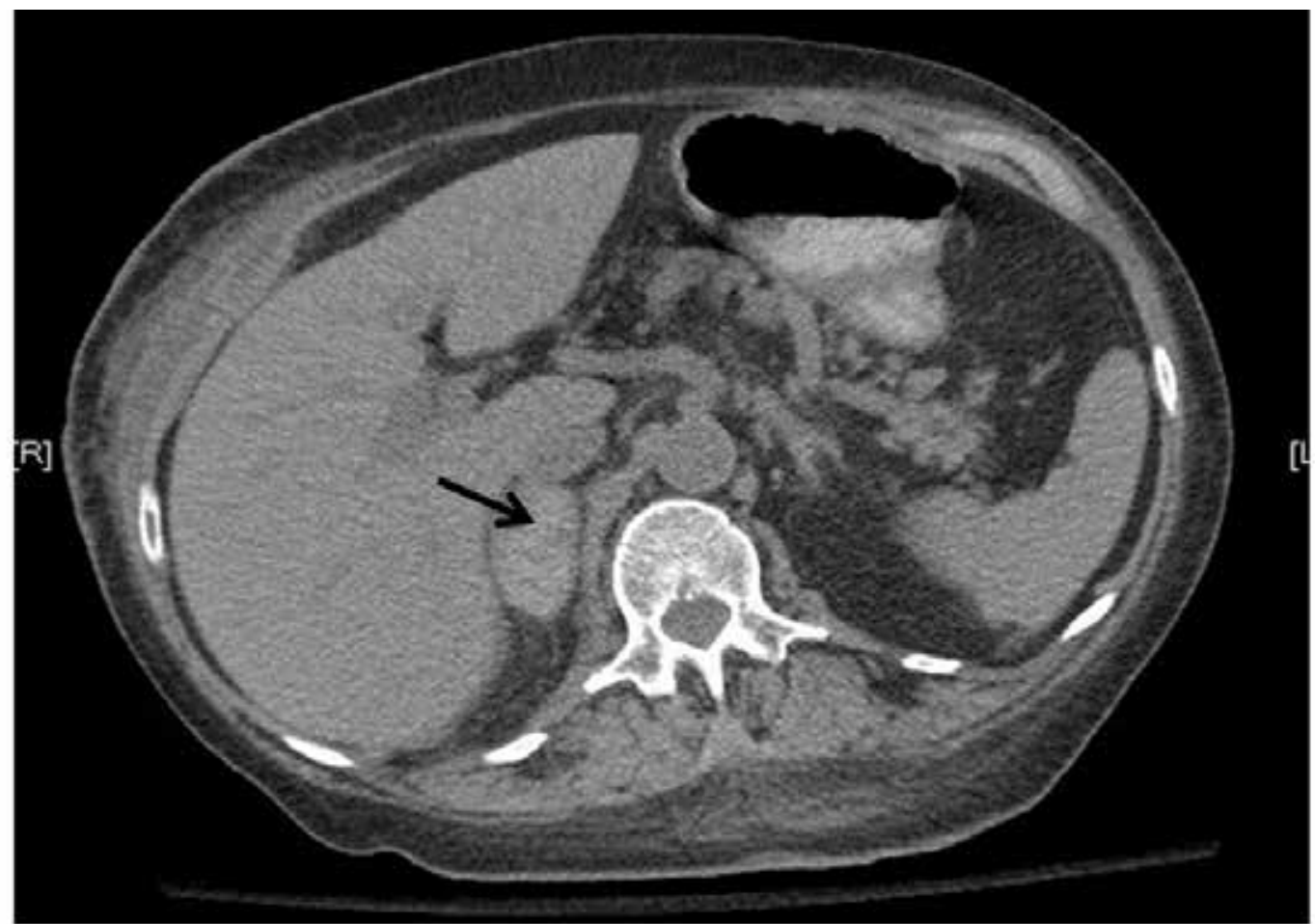

Figure 1.

To investigate potential complications, abdominal and renal ultrasounds were performed, and both showed no evidence of pyelonephritis. On the fourth day, she started to have severe right-sided abdominal pain, nausea and vomiting, with an unexpected drop in hemoglobin from 125 to $92 \mathrm{~g} / \mathrm{L}$. Abdominal computed tomography (CT) scan was arranged which revealed a right-sided pyelonephritis complicated by an acute right-sided adrenal hemorrhage (Figure 1). The patient was immediately started on dexamethasone after obtaining a baseline ACTH level of $7.6 \mathrm{pmol} / \mathrm{L}$ at $2 \mathrm{p} . \mathrm{m}$. (normal level less than $10.3 \mathrm{pmol} / \mathrm{L}$ according to local lab values). The following morning at 8 a.m. a $250 \mathrm{mcg}$ adrenocorticotropic hormone (ACTH) stimulation test was performed, followed by magnetic resonance imaging of the pituitary which demonstrated no abnormality. The diagnosis of adrenal insufficiency was confirmed by an inadequate response to ACTH serum cortisol levels 137, 350, and $433 \mathrm{nmol} / \mathrm{L}$, at 0,30 , and 60 minutes, respectively).

Accordingly, glucocorticoid replacement with hydrocortisone $15 \mathrm{mg}$ orally in the morning and $10 \mathrm{mg}$ in the evening, was started. Within 24 hours, her condition improved dramatically in terms of fatigue, dizziness, vomiting, weakness and anorexia. Her fever subsided and her blood work results returned to baseline. Follow-up imaging with abdominal CT one week later showed a decrease in the size of the previously identified adrenal hematoma. Prior to discharge, her hemoglobin concentration was $92 \mathrm{~g} / \mathrm{L}$, leukocyte count was 10 $\mathrm{X} 103 / \mathrm{L}$, and platelet count was $240 \times 10^{9} / \mathrm{L}$. Serum sodium was $139 \mathrm{mmol} / \mathrm{L}$, potassium was $4 \mathrm{mmol} / \mathrm{L}$, blood urea nitrogen was $9.8 \mathrm{mmol} / \mathrm{L}$, and creatinine was $159 \mu \mathrm{mol} / \mathrm{L}$.

A follow-up morning cortisol 6 weeks later (collected after withholding the evening dose of hydrocortisone the night before) was $148 \mathrm{nmol} / \mathrm{L}$. A decision was made, in consultation with an endocrinologist, to continue hydrocortisone therapy for another 6 months and to reassess whether it should be continued at that time.

\section{Discussion}

The adrenal glands are crucial to homeostasis and survival. They play a major role in stress response, maintenance of blood pressure, and electrolyte balance. They receive a rich blood supply, thus rendering them susceptible to vascular injury, hemorrhage, and metastatic deposits. ${ }^{2}$

$\mathrm{AH}$ is a rare condition found in $0.14 \%$ to $1.8 \%$ of hospitalbased autopsies. ${ }^{1}$ It is often picked up incidentally on CT imaging when patients present with non-specific symptoms and is therefore believed to be under-recognized. It can be bilateral or unilateral. Over a period of 25 years, the Mayo Clinic recorded 141 cases of AH; 78 (55\%) were bilateral, and $63(45 \%)$ were unilateral. Clinical features are usually vague 
and included abdominal pain, nausea, vomiting, fatigue, weakness, fever, and hypotension. Of these, the most common was abdominal pain. Possible laboratory abnormalities include hyponatremia, hyperkalemia, leukocytosis, and a drop in hemoglobin level, especially with acute $\mathrm{AH}$ and retroperitoneal hemorrhage. Clinical manifestations and biochemical abnormalities, however, are largely related to the underlying etiology of $\mathrm{AH} .^{3-7}$

Causes of adrenal hemorrhage can be classified as traumatic and non-traumatic. Major risk factors for non-trauma related include: anticoagulant drugs especially in the setting of heparin-induced thrombocytopenia, anti-phospholipid antibody syndrome, metastatic disease, sepsis, surgery, critical illness, and pre-existent adrenal mass. Traumatic causes are usually related to motor vehicle accidents or blunt trauma. ${ }^{6,7}$

Of note, Waterhouse-Friderichsen syndrome is a wellrecognized cause of adrenal hemorrhage in the setting of severe bacterial infection, typically with meningococcemia. This syndrome is characterized by petechial rash, coagulopathy, shock, and adrenal hemorrhage. Less commonly, it may result from infection due to Escherichia coli, Streptococcus pneumoniae, Neisseria gonorrhoeae, Haemophilus influenza, and Staphylococcus aureus. ${ }^{8}$

A CT scan of the abdomen is usually the investigation of choice in diagnosing $\mathrm{AH}$ in the absence of overt signs of bleeding. It usually shows asymmetric enlargement with a round or oval shaped gland with high attenuation compared to soft tissues. A streaky appearance of the perirenal fat may also be present. ${ }^{9-11}$

The mainstay of treatment in $\mathrm{AH}$ is to treat the precipitant factor and to give steroid replacement if accompanied by evidence of adrenal insufficiency. While most reports point towards survival benefit with corticosteroids in $\mathrm{AH}$ in the setting of anti-phospholipid antibody syndrome and after postoperative hemorrhage, steroids only provided minimal survival benefit in the setting of severe sepsis or sepsis and adrenal hemorrhage. Case reports have suggested that mineralocorticoid replacement may not necessarily be required in the absence of hypotension or electrolyte abnormalities. As for glucocorticoids, their use should be case-specific and patients should be screened by baseline cortisol levels and formal evaluation with cosyntropin-stimulation tests. ${ }^{7,12}$

In this case report, we describe a unique presentation of unilateral adrenal hemorrhage in association with Escherichia coli pyelonephritis and recent prolonged steroid use. Subnormal cortisol level with inadequate response to ACTH stimulation test is probably multifactorial; it is likely that the patient had pre-existent, bilateral adrenal atrophy from prolonged steroid exposure and the acute hemorrhage in the setting of pyelonephritis while being on unfractionated heparin for VTE prophylaxis resulted in a decompensated hypocortisolemic state. The described report reflects the challenge of early recognition and treatment of $\mathrm{AH}$, and reminds the physician to consider this diagnosis in the appropriate clinical setting. To our knowledge, this is the first case identifying unilateral $\mathrm{AH}$ in the context of previous steroid use and Escherichia coli pyelonephritis.

\section{References}

1. Xarli VP, Steele AA, Davis PJ, et al. Adrenal hemorrhage in the adult. Medicine (Baltimore) 1978; 57(3):211-221.

2. Longo DL, Fauci AS, Kasper DL, et al.editors. Harrison's principles of internal medicine.18th ed. New York: McGraw Hill; 2010:2940-2944.

3. Swift DE, Overholt EL, Travelli R. Methods of diagnosis of acute adrenal hemorrhage complicating anticoagulant therapy-abdominal CAT scanning. Wis Med J 1981;80(11):25-28.

4. Albert SG, Wolverson MK, Johnson FE. Bilateral adrenal hemorrhage in an adult: demonstration by computed tomography. JAMA1982;247(12):17371739.

5. Rosenberger LH, Smith PW, Sawyer RG, et al. Bilateral adrenal hemorrhage: the unrecognized cause of hemodynamic collapse associated with heparininduced thrombocytopenia. Crit Care Med 2011; 39(4):833-838.

6. Caron P, Chabannier MH, Cambus JP, et al. Definitive adrenal insufficiency due to bilateral adrenal hemorrhage and primary antiphospholipid syndrome. J Clin Endocrinol Metab 1998; 83(5):1437-1439.

7. Vella A, Nippoldt TB, Morris JC 3rd. Adrenal hemorrhage: a 25-year experience at the Mayo Clinic. Mayo Clin Proc Feb 2001;76(2):161-8.

8. Adem PV, Montgomery CP, Husain AN, et al. Staphylococcus aureus sepsis and the Waterhouse-Friderichsen syndrome in children. $N$ Engl J Med. Sep 22 2005;353(12):1245-1251.

9. Shah HR, Love L, Williamson MR, et al. Hemorrhagic adrenal metastases: CT findings. J Comput Assist Tomogr. Jan-Feb 1989;13(1):77-81.

10. Sacerdote MG, Johnson PT, Fishman EK. CT of the adrenal gland: the many faces of adrenal hemorrhage. Emerg Radiol. 2012 Jan;19 (1): 53-6111. Sinelnikov AO, Abujudeh HH, Chan D, et al. CT manifestations of adrenal trauma: experience with 73 cases. Emerg Radiol. Mar 2007;13(6):313- 318.

12. Jahangir-Hekmat M, Taylor HC, Levin H, et al. Adrenal insufficiency attributable to adrenal hemorrhage: long-term follow-up with reference to glucocorticoid and mineralocorticoid function and replacement. Endocr Pract Jan-Feb 2004;10(1):55-61 